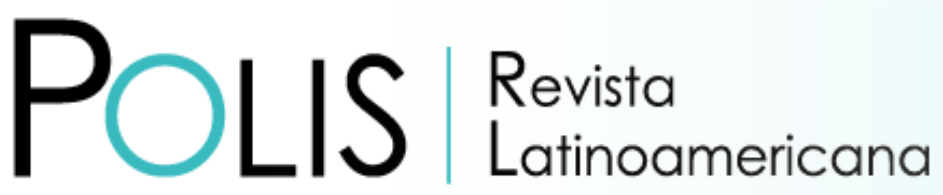

V20 $\mid$ N60 | 2021

DOI: $10.32735 /$ S0718-6568/2021-N60-1511

\title{
Coalizões de interesse e agências políticas relacionadas ao Complexo Garabi na fronteira Brasil e Argentina
}

\author{
Vanderlei Franck Thies \\ Instituto Federal Farroupilha, Alegrete, Brasil \\ Email:vftc3@yahoo.com.br \\ Laura Andrea Ebenau \\ Universidad Nacional de Misiones, Posadas, Argentina \\ Email: lauraebenau@gmail.com
}

Recibido: 26.05.2020 | Aceptado: 19.10.2020

\begin{abstract}
Resumo': Com o objetivo de compreender a intricada dinâmica social e os conflitos no desenvolvimento histórico decorrentes do projeto binacional Complexo Garabi, que envolve a construção de duas grandes barragens hidroelétricas (Garabi e Panambi) no trecho argentino e brasileiro do rio Uruguai, propõem-se nesse artigo analisar a configuração das disputas que tal projeto suscita. Utiliza-se o enfoque analítico da Advocacy Coalition Framework (Coalizões de Interesse) em combinação com a análise das distintas agências políticas e dos discursos que se reconhecem nos campos destas disputas. Privilegia-se na abordagem uma perspectiva comparada e diacrônica, onde se identifica duas coalizões em confronto e se observa que os conflitos, as agências e mobilizações, as narrativas e as políticas consideradas têm, por um lado, uma origem comum e uma dinâmica transnacional, mas por outro lado, também apresentam particularidades conforme os contextos locais e nacionais.
\end{abstract}

Palavras-chave: Coalizões de interesse; barragem hidroelétrica; perspectiva comparada; fronteira.

\section{Coaliciones de intereses y agencias políticas relacionadas al Complejo Garabi en la frontera de Brasil y Argentina}

Resumen: Con el objetivo de comprender la intricada dinámica social y los conflictos en el desarrollo histórico del proyecto binacional Complejo Garabi, que envuelve la construcción de dos grandes hidroeléctricas (Garabi y Panambi) en el trecho argentino y brasilero del río Uruguay, proponemos en este artículo analizar la configuración de las disputas que tal proyecto suscita. Se utiliza el enfoque analítico de la Advocacy Coalition Framework (Coaliciones de Intereses) en combinación con el análisis de las distintas agencias políticas y de los discursos que se reconocen en el campo de estas disputas. Privilegiamos en el abordaje una perspectiva comparada y diacrónica, donde se identifican dos coaliciones en confrontación y se observa que los conflictos, las agencias y movilizaciones, las narrativas y las políticas consideradas tienen, por un lado, un origen común y una dinámica transnacional, aunque, por otro lado, también presentan particularidades conforme a los

1 Versão preliminar deste trabalho foi elaborada para a XII Reunião de Antropologia do Mercosul, realizada em dezembro de 2017, na cidade de Posadas (Misiones, Argentina), sob o título de "Coalizões de Interesse e as Barragens Binacionais de Garabi e Panambi". 
contextos locales y nacionales.

Palabras clave: Coaliciones de intereses; represa hidroeléctrica; perspectiva comparada; frontera.

\title{
Advocacy Coalition Framework and Political Agencies related to the Garabi Complex on the Brazilian and Argentine border
}

\begin{abstract}
In order to understand the intricate social dynamics and conflicts in the historical development resulting from the binational Garabi Complex project, which involves the construction of two large dams (Garabi and Panambi) in the Argentine and Brazilian stretches of the Uruguay River, in this article we analyze the configuration of disputes that this project raises. The analytical approach of the Advocacy Coalition Framework is used in combination with an analysis of the different political agencies and discourses that are recognized in the fields of these disputes. A comparative and diachronic perspective is employed Two opposing coalitions are identified and we observe that conflicts, agencies and mobilizations, narratives and policies have, on the one hand, a common origin and a transnational dynamic, but on the other hand, they also present peculiarities, which vary according to local and national contexts.
\end{abstract}

Keywords: Advocacy coalition framework; Hydroelectric plant; Comparative perspective; Border.

Como citar este artículo:

Thies, V. F. y Ebenau, L. A. (2021). Coalizões de interesse e agências políticas relacionadas ao Complexo Garabi na fronteira Brasil e Argentina. Polis Revista Latinoamericana, 20 (60), 149-173. doi: http://dx.doi.org/10.32735/S0718-6568/2021-N60-1511

\section{Introdução}

A discussão sobre a questão energética no Brasil e na Argentina tem ocupado amplos espaços nas pautas sociais nas duas primeiras décadas deste século e, não raro, esses debates são marcados por intensas polêmicas e permeados por fortes conflitos. Por um lado, em nível dos estados nacionais, a questão energética volta a ser incorporada na agenda de forma intensa nos anos 2000, formalizada, no caso argentino, pelos convênios com o Paraguai, para impulsionar o projeto Corpus Christi e com o Brasil, através dos convênios da Emprendimientos Energéticos Binacionales S.A. (EBISA) com as Centrais Elétricas Brasileiras S.A. (ELETROBRÁS), para retomar o projeto atualmente denominado Complexo Garabi. Por outro lado, em sentido adverso ao interesse dos estados nacionais, diversos estudos evidenciam ampla gama de organizações e movimentos sociais que desde os anos 1980 se contrapõem a esses projetos, como, por exemplo, no caso da construção da Usina de Belo Monte, no Brasil, ou Corpus e Yacyretá, na Argentina (Fleury, 2013; Vieira, 2013; Lins Ribeiro, 1985), mas também em outros países, como México e Espanha (Poma, 2017). 
A relevância da temática abordada nesse trabalho também é revelada pela importância estratégica que a questão da energia ocupa em qualquer debate mais consistente sobre desenvolvimento. Além disso, as controvérsias envolvidas com a temática logo despertaram o interesse acadêmico relacionado aos grandes projetos energéticos no Brasil e Argentina. Alguns estudos trataram de problematizar as consequências sociais, os complexos e conflitivos processos de reassentamento, os efeitos sobre as populações indígenas e camponesas e as dinâmicas de organização de movimentos de oposição as represas, sendo alguns exemplos os estudos pioneiros de Bartolomé (1985), Lins Ribeiro (1985; 1999) e Sigaud (1988).

A produção acadêmica mais recente tem inovando na formulação de novas categorias conceituais a partir da construção de outras dimensões de análise ${ }^{2}$. Com base nesses aportes, no presente artigo tentaremos avançar numa primeira problematização, desde uma abordagem comparativa, sobre os processos que se desenvolveram até o ano de 2015 em torno do projeto binacional Complexo Garabi, que envolve a construção de duas grandes barragens (Garabi e Panambi). Essas barragens estão projetadas no trecho do rio Uruguai que é compartilhado por Brasil e Argentina, entre os estados do Rio Grande do Sul (Brasil) e Misiones e Corrientes (Argentina).

O presente trabalho, de caráter interdisciplinar, é fruto de esforço binacional em articular o trabalho de investigadores que têm se debruçado, até então cada qual em "seu lado do rio", sobre o caso desses projetos ${ }^{3}$. Nesse artigo apresentamos os resultados parciais das pesquisas que estão em curso, enfocando especialmente o período 2010-2015, quando o projeto foi retomado com grande intensidade pelos governos nacionais da Argentina e do Brasil (Paim, 2017). Trata-se de projeto polêmico e que tem gerado grandes controvérsias sociais nos dois lados do rio, sendo que no ano de 2015, em caráter liminar, o Ministério Público Federal brasileiro determinou a suspensão dos estudos para obtenção do licenciamento ambiental das obras, o que se detalhara mais adiante. Busca-se responder a seguinte questão: quais ideias dão unidade as coalizões de atores sociais envolvidos nas disputas relacionadas ao projeto binacional Complexo Garabi?

Nosso objetivo é identificar as coalizões de interesse e analisar as crenças que articulam esses grupos de atores que atuam organizadamente e impulsionam a dinâmica social e os conflitos no desenvolvimento histórico do projeto do Complexo Garabi. Da mesma forma, procura-se reconhecer o desenvolvimento das agências políticas e os discursos de atores que se constituem as margens dos partidos políticos e do Estado, mas que atuam para influir nos processos decisórios.

2 Entre eles podemos mencionar Oviedo (1997), Arach (2001; 2002; 2003), Magalhães (2007), Balazote et al. (2001), Fleury (2013) e Brites (2014), Prates e Rodrigues (2020), Florit e Bittencourt (2020), Souza e Brites (2017) e Catullo (2017; 2020). O espaço disponível nos marcos deste artigo não permite uma revisão exaustiva destes trabalhos, todavia, alguns deles, serão utilizados ao longo da exposição.

3 O material empírico produzido ao longo das respectivas pesquisas (uma de caráter antropológica e outra sociológica) foi revisado a luz de um novo marco interpretativo, resultando na presente elaboração. 
A abordagem inicial é feita a partir das referências de análise de políticas públicas de Advocacy Coalition Framework, que denominaremos de coalizões de interesse. A origem dessa abordagem está associada às formulações de Paul A. Sabatier e Hanck C. Jenkins-Smith e remonta aos anos da década de 1980. Segundo Weible e Sabatier (2007), os estudos ancorados por essa abordagem têm tratado principalmente das políticas energéticas e ambientais, principalmente nos EUA, Canadá e Europa, apesar de ser crescentemente aplicada por pesquisadores de outras áreas geográficas e em outras temáticas. Weible et al. (2009) destacam que as hipóteses mais comumente testadas por estudos que usam essa abordagem se referem as mudanças ocorridas nas políticas públicas, os processos de aprendizagem e a estabilidade de coalizões políticas em situações de conflito. Pretende-se também avançar na formulação de novos referenciais analíticos, verificando a apropriação e os limites desta abordagem para os casos estudados.

A metodologia para sua realização integrou revisão bibliográfica e obtenção de dados primários, especialmente através de análise documental e de materiais jornalísticos e institucionais. Além disso, os autores participaram e registraram diversos eventos relacionados a questão, levantando dados que contribuíram para as reflexões aqui apresentadas.

O trabalho está organizado em cinco partes, além dessa introdução. Na segunda seção são apresentados os pressupostos e fundamentos do modelo de coalizão de interesses, que é complementado na terceira seção com o detalhamento de sua estrutura e dinâmica analítica, sendo esse o referencial teórico utilizado na análise. Na quarta seção apresenta-se os resultados do trabalho, contemplando o contexto e a trajetória das experiências analisadas e em seguida os parâmetros, as crenças e as coalizões estabelecidas entre os atores do subsistema político. Por fim apresentamos as considerações finais, destacando algumas ponderações e apontando as questões a serem trabalhadas no aprofundamento dos estudos.

\section{Marco conceitual do modelo de coalizões de interesse}

De acordo com Weible e Sabatier (2007) o quadro analítico fornecido pelo modelo de coalizões de interesse, mostra-se mais adequado à análise das políticas públicas em situações que envolvem divergências de entendimentos, conflitos e disputas. Trata-se de uma abordagem que reconhece que essas políticas resultam de tensionamentos sociais que permeiam a interpretação das distintas situações históricas, a definição dos problemas e das propostas de intervenção. Segundo Sabatier e Jenkins-Smith (1999), também ganha destaque o papel exercido pelos aprendizados e o papel do conhecimento no processo político e na mudança das políticas públicas.

De acordo com Weible et al. (2009) o modelo da coalizão de interesses tem como hipóteses subjacentes as seguintes premissas em relação as políticas públicas: a relevância das informações técnicas e científicas nos processos; análises de ao menos dez anos, para se entender determinada mudança; a unidade básica de análise são os subsistemas da 
política pública; os processos envolvem diversos atores (individuais ou coletivos, estatais ou não, diferentes níveis de governo, cientistas, mídia, organizações não governamentais, movimentos sociais, etc.).

Os aspectos comportamentais dos diversos atores constituem um dos fundamentos da abordagem, que pressupõem que os agentes, sejam eles públicos ou privados, atuam de acordo com suas crenças e seus valores. Com base em um sistema hierarquizado de crenças esses sujeitos interpretam o mundo, delimitam problemas, constituem alianças e coordenam ações com outros agentes, procurando conformar as políticas públicas em um sentido específico. Esse não é um processo linear, pois esse grupo de atores é confrontado por outros grupos organizados, que possuem crenças comuns, interpretações e propostas divergentes. Essas agrupações, que agem coordenadamente, são denominadas de coalizões de interesse (Sabatier e Jenkins-Smith, 1999; Weible e Sabatier, 2007).

O modelo da coalizões de interesses pressupõe que os indivíduos são racionalmente motivados, mas com limitações, em função de restrições em sua capacidade de compreender o mundo complexo em que vivem e de apreender e adquirir novas informações. Eles tendem a ignorar as informações que contrariam suas crenças e a aceitar mais facilmente as informações que as reforçam. Isso leva os indivíduos a ter um comportamento de desconfiança em relação a quem possui crenças distintas das suas e reforçar os laços com quem possui crenças similares (Weible et al., 2009). Assim, os atores estariam inclinados a constituir alianças (coalizões de interesse) com sujeitos possuidores de crenças similares às suas.

Cabe destacar que o modelo não dicotomiza, em termos absolutos, o Estado e a Sociedade, visto que diferentes coalizões podem, simultaneamente, ser compostas por entes estatais e não estatais. Assim, as coalizões resultam do encontro e composição de alianças entre agentes políticos de diferentes origens e distintas identidades. Portanto, o elemento definidor do caráter e da identidade do agente político não está associado diretamente a sua origem, ou ao grau de institucionalização, senão à suas crenças e valores.

Em termos gerais, o fundamento central do modelo de análise proposto está na descrição da origem e na caracterização da dinâmica das coalizões existentes em torno de certa política pública, focando sua análise nas crenças, nas ideias e nos valores dos atores envolvidos nas distintas coalizões. Essas crenças são consideradas como lentes interpretativas e como os principais guias das ações (causal driver) dos indivíduos e grupos que disputam e influenciam os processos de formulação e mudanças de uma política pública. Parte-se da premissa que os programas e as políticas públicas são melhor compreendidos como tradução de crenças, das práticas e das diferentes agências. 


\section{Quadro analítico do modelo de coalizões de interesse}

O modelo de coalizões de interesse passou por alguns ajustes ao longo do tempo, mas manteve sua estrutura geral inalterada. Uma análise pormenorizada desses ajustes extrapolaria os limites desse trabalho, por isso tomaremos como referência a síntese do modelo apresentada por Weible et al. (2009) na Figura 1.

Nesse modelo os indivíduos possuem um sistema de crenças baseado em três níveis, sendo a mais elevada a deep core beliefs (DCB), ou crenças profundas, que são mais estáveis e abrangentes. São crenças normativas, muito resistentes a mudança, envolvendo as prioridades em relação a valores fundamentais, como por exemplo, as distinções entre esquerda e direita, relação entre maior ou menor controle dos mercados pelo Estado, etc. O segundo nível é composto pelas policy core beliefs (PCB), ou crenças em relação a política pública em questão. Elas delimitam a amplitude substantiva e geográfica do subsistema político, além de informar como devem ser as políticas públicas. Frente a novas experiências e informações, as PCB são mais flexíveis e menos resistentes a mudanças que as DCB. No último nível estão as secondary beliefs (SB), ou crenças secundárias, que em comparação as PCB representam crenças com escopo substantivo e geográfico mais limitado e de base mais empírica. Elas incluem as preferências dos participantes em relação aos instrumentos governamentais específicos usados para a resolução dos problemas. Esse é o nível de crenças mais susceptível a mudanças frente a novas informações ou eventos (Weible e Sabatier, 2007; Sabatier e Jenkins-Smith, 1999; Weible et al., 2009).

Figura 1

Fluxograma do modelo de coalizão de interesse.

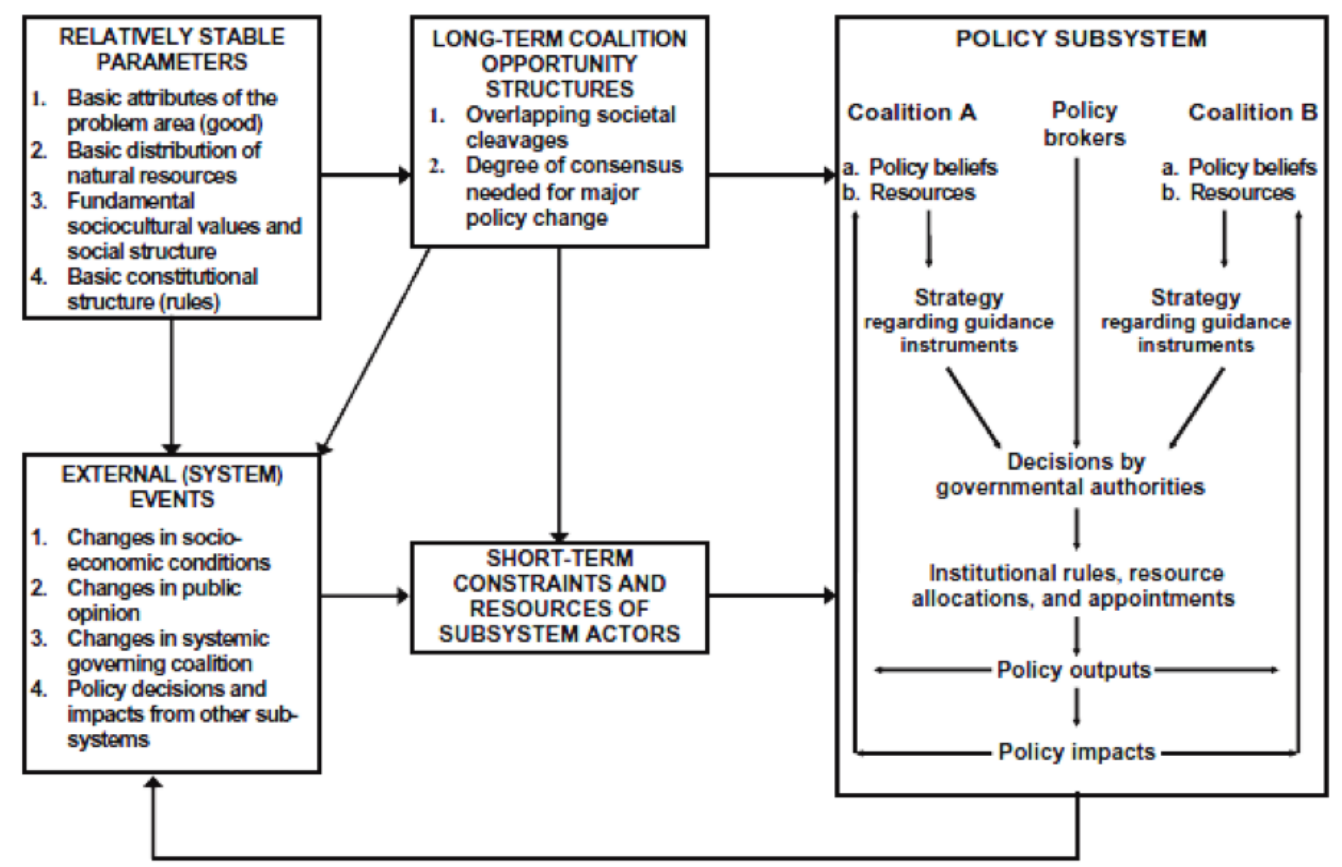

Fonte: Weible, et al. (2009, p. 123). 
A constituição e as transformações de uma política pública se desenvolvem em um subsistema político específico, que está imerso em um ambiente político mais amplo. Esses subsistemas operam e são delimitados por parâmetros relativamente estáveis e eventos externos, que estruturam as oportunidades de longo prazo das coalizões e limitam os recursos dos atores no curto prazo. Assim, o sucesso dos participantes do processo político depende de sua capacidade de traduzir e transmitir suas crenças para as políticas públicas em um determinado subsistema. Para aumentar suas chances os participantes procuram aliados, com crenças políticas semelhantes, com quem coordenam suas ações em coalizões de interesse (Weible e Sabatier, 2007) ${ }^{4}$.

Os participantes do subsistema, organizados em coalizões, tentam influenciar as crenças dos demais atores e disputam os rumos da política, desencadeando ações e defendendo seus interesses nos mais diversos espaços, como as instâncias legislativas, varas judiciais, agências de regulação e na mídia. Esses espaços são compreendidos como arenas, em que ocorrem as disputas. As coalizões tentam incidir sob as percepções de quem toma as decisões, procurando influenciar na modelagem do processo político e em seus resultados, através de mudanças nas regras institucionais, ou na alocação de recursos. Isso gera resultados políticos e impactos dentro e fora do subsistema (Weible e Sabatier, 2007).

Os Parâmetros Relativamente Estáveis (relatively stable parameters) são elementos que permanecem sem alterações significativas por longos períodos de tempo e que estruturam a natureza do problema, condicionam a distribuição dos recursos entre os participantes, estabelecem os procedimentos para as mudanças políticas e decisões coletivas e delimitam, em termos gerais, os valores que conformam as políticas. Em função de sua estabilidade ao longo do tempo e da maior resistência às mudanças, usualmente, não são visados pelos participantes. Ou seja, esses parâmetros englobam os traços constitutivos fundamentais do problema, envolvendo a dimensão da distribuição dos recursos naturais, os valores sociais fundamentais e a estrutura social, além dos parâmetros legais mais importantes. Eles são compreendidos como o ambiente mais geral em que se inserem os diversos subsistemas políticos existentes em determinado período.

Esses parâmetros emolduram o processo de definição das políticas em subsistemas políticos, sendo esses delimitados territorial e tematicamente. Algumas vezes é difícil definir os limites geográficos e substantivos do subsistema político, em função de alguns deles estarem incluídos nos limites de outros subsistemas e, também, em função de muitos participantes

\footnotetext{
4 Por exemplo, Barcelos (2010) ao estudar a silvicultura na área ambiental do Rio Grande do Sul (RS) identificou uma coalizão de interesse que denominou de Coalizão Pró-expansão da silvicultura. Ela tinha como DCB as ideias de que o desenvolvimento da silvicultura, aliada a instalação de grandes indústrias de celulose, representava uma real possibilidade de desenvolvimento para a estagnada região da Metade Sul do RS. Com base nisso, advogava a necessidade de políticas públicas que dessem suporte e impulsionassem a silvicultura na referida região, sendo essas ideias expressão da PCB. Essa coalização foi confrontada por outros atores, com outras crenças, que compartilhavam DCB que sobrepunham a preservação do Bioma Pampa à expansão da silvicultura. Com base nisso as políticas públicas propostas tinham caráter regulatório da silvicultura e deveriam ser restritivas a essa atividade na referida região. Essas distintas crenças estavam claramente em conflito e guiaram ações contraditórias das duas coalizões em relação às políticas públicas para a silvicultura.
} 
serem ativos em mais de um subsistema (Weible e Sabatier, 2007). Por isso não existe uma regra única para a delimitação, o que confere maior aplicabilidade ao modelo mas, por outro lado, torna essa tarefa mais trabalhosa.

No caso aqui abordado, considerando que os avanços iniciais na construção de movimentos de oposição as represas ${ }^{5}$, os processos de integração fronteiriça desde abajo que esses atores propiciaram, especialmente desde os anos 1980 (Abínzano, 2000), somada a exitosa experiência publicitária na província de Misiones (Argentina), que conseguiu bloquear a realização do projeto hidroelétrico de Corpus Christi, expressam a constituição de uma tradição de luta contra as barragens, que foi se conformando em ambos lados do rio. Com intercâmbios mais ou menos constantes ao longo do tempo, estas organizações e movimentos de oposição compartilham uma narrativa, certas estratégias de confrontação e informação, dinâmicas de organização e práticas de luta que são atualizadas e ressignificadas, de acordo com o contexto específico em que estão inseridas, para assim, desde as ações localizadas em territórios demarcados por limites formais dos estados nacionais, impactar sobre os processos mais globais de disputas e construção das políticas. De acordo com o modelo analítico adotado, pode-se apontar que a existência destas conexões, processos de integração e tradição de lutas articuladas, possibilitou a construção de coalizões locais que foram se transformando em transnacionais, que permitem reconhecer um subsistema político regional, construído em torno das proposições de um ambientalismo global (Barros, 1996) e pela atuação dos movimentos sociais de oposição as barragens.

Segundo Sabatier e Jenkins-Smith (1999) existem três mecanismos que articulam mudanças nas crenças e nas políticas: choques externos ${ }^{6}$, hurting stalemate ${ }^{7}$ (incômodo beco sem saída) e o acúmulo de evidências científicas e técnicas ${ }^{8}$. Ao revisar o quadro analítico da coalizão de interesses, Sabatier e Weible (2007) vão reconhecer a importância de choques internos e acordos negociados entre as coalizões como importantes vetores de mudanças nas políticas. Por fim, os conflitos gerados pelas discordâncias entre as coalizões são mediados por policy brokers, que podem ser compreendidos como determinados

\footnotetext{
5 Bartolomé (2001) chama a atenção para o desenvolvimento orgânico dos movimentos brasileiros que canalizaram suas demandas através dos meios de comunicação, além de ações no campo político e legal e episódios de oposição ativa. A prolongada luta das populações brasileiras afetadas por barragens na bacia do rio Uruguai, desde os anos 1980, constitui um importante antecedente e referência para as práticas de movimentos de oposição no contexto argentino e pontualmente em Misiones.

6 Ocorrem fora do subsistema político e podem mudar a distribuição de recursos, ou abrir e fechar arenas, ajustando o equilíbrio de poder entre as coalizões, podendo alterar também o centro das crenças políticas e, potencialmente, gerar mudanças substantivas. Os choques externos podem alterar rapidamente a relação de dominância entre as coalizões.

7 Isso ocorre quando a situação torna-se inaceitável para as distintas coalizões e quando suas formulações são insuficientes para dar conta do problema. Quando as coalizões estiverem nessa situação de impasse, por não aceitarem a situação, mas sendo insuficientes suas proposições, existirão condições para mudanças substantivas nas políticas.

8 Essa situação ocorre com o acúmulo gradativo de evidências científicas, que através do processo de aprendizagem política afeta as crenças dos atores dentro do subsistema, o que pode levar a mudanças, maiores ou menores. Esse aprendizado é inibido pela filtragem que os sujeitos que compõem as coalizões fazem em relação às informações que envolvem o conflito. Isso torna lentas as mudanças nas crenças políticas dos indivíduos e, em consequência, nos subsistemas políticos, o que implica que mudanças através dos aprendizados ocorram apenas em longos períodos de tempo.
} 
agentes políticos que fazem a intermediação, ou mediação do conflito. Diversos atores podem desempenhar esse papel, que visa constituir um compromisso razoável entre as coalizões hostis.

Ainda, cabe destacar que, em termos metodológicos, as elaborações mais atuais dos autores que formularam o modelo, destacadamente, Jenkins-Smith et al. (2014), Moyson, Scholten e Weible (2017) e Weible (2018), exploram os limites e potencialidades do uso combinado do modelo de coalizões de interesses com outras abordagens', mas que, para o caso estudado, não alteram substantivamente o modelo utilizado.

Na sequência apresentam-se os resultados da aplicação do modelo ao caso estudado. No primeiro bloco, apresenta-se os aspectos históricos e a trajetória das iniciativas relacionadas a construção de barragens no trecho binacional do rio Uruguai, contextualizando a evolução do projeto. No segundo bloco, apresenta-se os parâmetros utilizados para a categorização das crenças, bem como a classificação dos atores e a caracterização das coalizões que interagem nas disputas relacionadas a construção de barragens nesse trecho específico do rio Uruguai.

\section{Contexto e trajetória dos Projetos Garabi e Panambi}

O rio Uruguai nasce da junção dos rios Canoas e Pelotas, na divisa entre os estados do Rio Grande do Sul e Santa Catarina, no Brasil. Sua extensão total é de 1.770 km, sendo parte em território exclusivamente brasileiro e parte compartilhada com Argentina. É um dos cursos de água mais importantes da hidrografia da América do Sul.

O mapeamento do potencial hidrelétrico da Bacia internacional do rio Uruguai foi iniciado nos anos de 1970. No ano de 1986 esses estudos foram complementados, tendo, portanto, pouco mais de 30 anos. Na década de 1970 apontava-se a possibilidade da instalação de 25 grandes represas ao longo de todo rio Uruguai, sendo três delas binacionais (Paim, 2017).

No ano de 2008 a ELETROBRÁS e a EBISA contrataram estudos para atualização do potencial hidroelétrico do rio. Em novembro de 2010 foi apresentado o novo Inventário Hidroelétrico do trecho do rio Uruguai compartilhado por esses dois países (ELETROBRÁs; EBISA, 2010). Na parte inicial do novo inventário destaca-se a ênfase dada às questões ambientais, reconhecendo as fragilidades dessa dimensão nos estudos das décadas passadas e apontando para a necessidade de considerar os novos marcos regulatórios em relação à construção de barragens. Aponta-se a importância da preservação do Salto do Yucumã e também a busca da redução do número de ribeirinhos afetados na ponderação dos novos projetos. Nessa fase foram supostas e estudadas diversas possibilidades de localização e de tamanho de barragens. Essas alternativas foram comparadas entre si, com objetivo

9 Sobre o uso combinado do modelo de coalizões com outras abordagens, sugere-se ver também: Vieira e Gomes (2014), Blake, Nahrath e Ingold (2020) e Vieira (2020). 
de verificar as mais viáveis, considerando custos de implantação, benefícios energéticos e impactos socioambientais. Para o desenho das alternativas foram utilizados dados secundários, complementados com alguns estudos de campo, considerando informações cartográficas, hidrometeorológicas, geológicas e geotécnicas, socioambientais e de possibilidades de uso da água. O estudo compreendeu um trajeto de aproximadamente $725 \mathrm{~km}$ do rio Uruguai, que vai da foz do rio Peperí-Guaçu até a foz do rio Quaraí. Nesse trecho, o rio tem em sua margem esquerda, o estado brasileiro do Rio Grande do Sul e, na margem direita, as províncias argentinas de Misiones e Corrientes (ELETROBRÁS; EBISA, 2010).

O aprofundamento dos estudos levou a seleção de duas possibilidades de locais para as obras, sendo Garabi, que ficaria a aproximadamente a 6 km rio abaixo da cidade de Garruchos (Brasil e sua homônima Argentina), com nível máximo de água de $89 \mathrm{~m}$ em relação ao nível do mar e também Panambi, aproximadamente $10 \mathrm{~km}$ rio acima da cidade de Porto Vera Cruz (Brasil) e Panambi (Argentina), com nível de 130m. Juntos, os lagos dessas represas inundariam 96.960 ha e a construção de ambas representaria um custo superior a 5,2 bilhões de dólares (ELETROBRÁS; EBISA, 2010). Trata-se, portanto, de projetos de grande escala, seguindo a clássica definição de Lins Ribeiro (1985).

A nova configuração proposta no inventário de 2010 reduz de três para dois os projetos de barragens, eliminando o projeto de São Pedro, previsto em 1974 para a cota 52m. Além disso, são alteradas as cotas de Garabi e Panambi, preservando o Salto do Yucumã, que seria coberto no projeto de 1974 e também livrando de inundação a área urbana das cidades de Porto Vera Cruz (Brasil) e Panambi (Argentina). Nessa nova configuração a barragem de Garabi ocuparia ao todo 80.273 hectares, tendo potência instalada de $1.152 \mathrm{MV}$ e um custo total estimado de 2,7 bilhões de dólares. Com essa dimensão, nos dois países, atingiria em áreas urbanas 2.100 pessoas e em área rurais mais 3.800 pessoas. No caso de Panambi, seriam ocupados ao todo 46.460 hectares, tendo potência instalada de $1.048 \mathrm{MV}$ e um custo total estimado de 2,4 bilhões de dólares. Atingindo diretamente 1.300 pessoas de áreas urbanas e 5.400 pessoas de áreas rurais. Considerando as duas barragens, as áreas urbanas de quatro cidades argentinas e duas brasileiras seriam parcialmente atingidas e uma cidade Argentina (Alba Posse) e outra brasileira (Porto Mauá) seriam integralmente transferidas (ELETROBRÁs; EBISA, 2010).

Em novembro de 2012 a Comissão Técnica Mista (ELETROBRÁS e EBISA) aprovou a minuta de contrato para a realização dos estudos de viabilidade e dos projetos básicos, estudos ambientais e de comunicação social de Garabi e Panambi. Em dezembro de 2012 o Consórcio Energético Rio Uruguai (formado pelas empresas Consular, Engevix, Grupo Consultor Mesopotamico, IATASA, Intertechne e Latinoconsult), vencedor da licitação internacional, assinou os contratos para a realização desses estudos e avançar na elaboração dos projetos. A previsão era que o tempo de realização fosse de 21 meses. 
Esses estudos se encaminharam mesmo estando em vigência na província de Misiones, desde o ano de 2011, a Lei IV - № 56 denominada "Nueva Coparticipación Económica para Misiones: La Soberanía Energética Proceso Decisional del Patrimonio Natural de los Misioneros". Essa norma determina a obrigatoriedade da participação do povo de Misiones e a intervenção ativa do Estado provincial no processo de avaliação e decisão sobre a viabilidade de projetos hidroelétricos no território. O descumprimento desta regulamentação foi motivo de intensas mobilizações nos anos 2013 e 2014, como será referido mais adiante. O não cumprimento afetava especificamente o Artigo 4 da referida lei, que define que:

"La intervención del Estado misionero, a través del Gobierno provincial y la Cámara de Representantes, es de carácter obligatorio y previa a cualquier decisión de carácter provincial, nacional y/o binacional, respecto de emprendimientos hidroeléctricos, incluyendo la formulación del anteproyecto de los mismos. Esta intervención procede respecto de todo emprendimiento hidroeléctrico actualmente en estudio y a los que en el futuro se proyecten" (Artigo 4, LeilV-N56/2011 - Provincia de Misiones) (Grifos nossos).

Por sua vez, o Governo do Estado do Rio Grande do Sul, em junho de 2014, instituiu, por decreto, a Política Estadual de Direitos dos Atingidos por Barragens. Esse decreto determina o estabelecimento de um Fórum de Participação Permanente, para cada projeto hidroelétrico no Estado, com a participação paritária entre sociedade civil, Governo Federal, Governo do Estado e empreendedores, para decidir a viabilidade da obra e as possíveis reparações aos atingidos (RS DECRETO No 51.595, 2014). Destacamos essa arena como espaço que possibilitou a emergência de um Policy Brocker (Weible et al., 2009) entre os lados argentino e brasileiro.

Nos meses de setembro e outubro de 2014 o Centro de Informação e Participação Pública do Consórcio Energético do rio Uruguai passa a divulgar o início da realização do Cadastro Socioeconômico e Imobiliário nas áreas atingidas pelas barragens. Segundo Paim (2017) o consórcio realizou cerca de 200 reuniões informativas, em 2013 e 2014, nas áreas dos empreendimentos dos dois países, com o objetivo de informar a comunidade sobre o andamento dos projetos. A previsão era concluir esse cadastramento em junho de 2015 . 0 cadastro socioeconômico tem por objetivo recolher informações básicas de identificação e das condições e modos de vida da população impactada. Já o cadastro imobiliário e fundiário visa recolher dados sobre as características de cada imóvel, aspectos documentais dos proprietários ou posseiros e informações sobre o uso e a ocupação do solo.

Atualmente todos os estudos estão paralisados, em função de decisão judicial da $1^{a}$ Vara de Justiça Federal de Santa Rosa (Brasil), que determinou liminarmente, em 27 de janeiro de 2015, a suspensão dos estudos de viabilidade de Panambi na Cota 130m e impedindo que - IBAMA conceda licenças ambientais ao empreendimento, sob alegação de impactos ao Parque Estadual do Turvo (MPF, 2015). A ação partiu do Ministério Público Federal de Santa Rosa e também foi assinada pelo Ministério Público do Estado do Rio Grande do Sul, sendo confirmada a suspensão dos estudos pela $4^{\circ}$ turma do Tribunal Regional Federal, em agosto de 2017 (MPF, 2017), cabendo ainda recurso ao Supremo Tribunal Federal. Frente a isso a ELETROBRÁS optou por também suspender a continuidade dos estudos de Garabi, por compreender ser mais adequado que ambos ocorram de forma paralela. 


\section{Parâmetros, crenças, coalizões e agências políticas}

Os Parâmetros Relativamente Estáveis do Sistema (PRES) foram delimitados com base no estudo de diversos documentos ${ }^{10}$. Eles permitiram derivar os seguintes aspectos em relação a cada uma das quatro dimensões:

Os atributos básicos do problema englobam as controvérsias sobre o crescimento da demanda nacional por energia elétrica, decorrente das atividades produtivas, sobretudo industrial e secundariamente do consumo doméstico, que ampliam a pressão pela construção de novas barragens. No Brasil, a matriz energética está centrada na geração por hidroelétricas, com várias barragens sob controle do capital funcionando no rio Uruguai. A Argentina apresenta expressiva participação das hidroelétricas na matriz energética, mas não possui hidroelétricas funcionando no trecho binacional do rio Uruguai e possui poucas alternativas de rios para construção de novas barragens na região de fronteira com o Brasil.

Nessa região de fronteira, as margens do rio Uruguai são ocupadas por pequenos agricultores em ambos países (no caso do agricultores argentinos, destaca-se a expressiva fragilidade dos títulos de propriedade) onde também ocorre a presença dispersa e desorganizada de pescadores artesanais. Importantes parques funcionam na zona atingida pelo Complexo Garabi: o Parque Estadual do Turvo - Unidade de Conservação ambiental com proteção integral, sob controle público, onde se localiza o Salto do Yucumã; e ao leste da província de Misiones (Argentina) a Reserva de Biosfera Yabotí e os Parques Provinciales Esmeralda e Moconá com diversos serviços turísticos em funcionamento junto ao Salto Moconál1, importante atrativo turístico.

O contexto sociocultural dos dois países na região de abrangência do Complexo Garabi apresenta em comum o fato de serem regiões com baixos índices de desenvolvimento, além da presença e forte atuação da igreja católica e várias igrejas evangélicas e a presença dispersa de diversos empreendimentos de lazer associados ao rio ao longo do seu curso. No lado brasileiro os agricultores possuem frágil organização, com pouca experiência local de enfrentamento a grandes contendas, mas são apoiados pela experiência de lutas anteriores de outros agricultores contra barragens em outros trechos do rio Uruguai. No lado argentino existem processos mais intensos de organização local, com maior disposição para o enfrentamento ao projeto e intensa experiência provincial de enfrentamento político a projetos dessa natureza, que se originaram da resistência à construção de barragens no rio Paraná.

10 Tratado Brasil Argentina sobre uso compartilhado rio Uruguai. DECRETO PRESIDENCIAL No 88.441, de 29 de junho 1983; Plano Nacional de Energia Elétrica 1987 - 2010 (1987); Plano Nacional de Energia 2030 (2007); Protocolo Adicional ao Tratado Brasil Argentina sobre uso compartilhado do rio Uruguai (2007); DECRETO PRESIDENCIAL N 7.342 , de 26 de outubro de 2010; Inventário Hidroelétrico do rio Uruguai (publicado em 2010); Relatório Final - Conselho de Defesa dos Direitos da Pessoa Humana, Comissão Especial "Atingidos por Barragens" (2010); Plano estratégico de desenvolvimento do COREDE Fronteira Noroeste 2010-2030 (2010); Plano estratégico de desenvolvimento do COREDE Celeiro 2010-2030 (2010); Carta aberta sobre Barragens do IV Fórum Social Missões (2012); PORTARIA INTERMINISTERIAL 340, de 01 de junho de 2012; Manifesto da plataforma operária e camponesa para a energia sobre as medidas da renovação das concessões do setor elétrico brasileiro (16 de outubro de 2012); Plano estratégico de desenvolvimento do COREDE Fronteira Noroeste 2015-2030 (2017).

11 Salto Moconá e do Yucumã são as denominações na Argentina e no Brasil para o mesmo salto, presente no rio Uruguai. 
No quadro 1 se apresentada o panorama normativo brasileiro e argentino em relação a construção de barragens para geração de energia elétrica.

\section{Quadro 1}

\section{Estrutura Constitucional e normativa no Brasil e Argentina.}

\begin{tabular}{|l|l|}
\hline \multicolumn{1}{|c|}{ BRASIL } & \multicolumn{1}{c|}{ ARGENTINA } \\
\hline - A ELETROBRÁS foi criada em 1962, é & - Criação da EBISA por Decreto Presidencial Nº \\
uma sociedade de economia mista e de & 616/1997, com participação estatal majoritária (99\% \\
capital aberto sob controle acionário do & das ações pertencem a Secretaría de Energía e o \\
Governo Federal brasileiro (possui 52\% das & restante a Nucleoelétrica Argentina S. A.). Tem a \\
ações). A companhia controla diversas & responsabilidade da comercialização da energia \\
subsidiárias que atuam no ramo da gera- & elétrica gerada pelos empreendimentos binacionais e \\
ção, transmissão e distribuição de energia & conexões internacionais.1 \\
elétrica. & - Em 2003, com a criação do Plan Energético Nacio- \\
- Política Nacional de Recursos Hídricos, & nal foi criado o Programa Nacional de Obras Hidroe- \\
Lei no 9.433/97; Política Nacional de Meio & létricas (Resolución 762/2009). \\
Ambiente; Resoluções do Conama; Novo & - Leis Estaduais (Misiones): \\
Modelo do Mercado de Energia Elétrica & Ley Provincial IV- N56 (201 1) "Nueva Coparticipación \\
(Lei no. 8.987/95 e Lei no. 9.074/95); Regras & Económica para Misiones: La Soberanía Energética \\
de licenciamento ambiental. - DECRETO & Proceso Decisional del Patrimonio Natural de los Misio- \\
PRESIDENCIAL No 88.441/1983; & neros". \\
- DECRETO PRESIDENCIAL No 7.342/2010; & Com a sanção da Lei Nº 3220 (1995) se estabeleceu \\
- PORTARIA INTERMINISTERIAL 340/2012; & o regime de consulta popular e plebiscito obrigató- \\
- DECRETO do Estado do RS Nº 51.595, de & rio e vinculante, aceitando ou não a construção da \\
23 de junho 2014; & barragem Corpus Christi. O desenvolvimento dessa \\
& experiência plebiscitária em 1995 foi constituindo uma \\
& tradição de luta contra as barragens (Ebenau, 2016). \\
\hline
\end{tabular}

Fonte: elaboração própria.

Depois dessa apresentação sintética da distribuição dos recursos naturais e de alguns valores e características socioculturais em ambos os lados do rio, conforme o modelo de Sabatier e Jenkins-Smith, deve-se avançar na construção de um mecanismo de interpretação das informações coletadas. Segundo Araújo (2007) a construção do código de análise documental é um dos momentos mais complexos no modelo de coalizão de interesses. Segundo esta abordagem, a constituição desse código é fundamental para a delimitação das crenças e a categorização das mesmas, bem como para o processo de identificação dos atores envolvidos no subsistema político e a configuração das coalizões. Aqui reside um elemento de tensionamento com a formulação do modelo, que decorre do entendimento que as crenças são reelaboradas permanentemente, sendo constantemente disputadas. Assim, elas podem inclusive aparecer, momentaneamente, como contraditórias em um mesmo setor, o que complicaria a constituição de um código interpretativo. Nossas reflexões atuais apontam para a possível incorporação de procedimentos analíticos complementares, como por exemplo a análise das narrativas, ou outras formas de delimitação e categorização das crenças. 
Considerando os dados disponíveis operacionalizamos a delimitação preliminar das coalizões, seguindo a sugestão de procedimento realizada por Vieira (2013), ao estudar a construção, no Brasil, da Usina de Belo Monte. O autor sugere que a resposta as questões mais polêmicas permeia as estruturas das crenças dos atores envolvidos e sua observação permite inferir o conteúdo substantivo dessas crenças, tanto dos atores como das coalizões. No caso referido ele identificou as seguintes questões: O projeto é viável do ponto de vista técnico e socioambiental? Quem irá se beneficiar de fato com a construção da usina? O projeto tem sido conduzido de forma democrática ou autoritária pelos seus responsáveis? No caso dos projetos Garabi e Panambi, entende-se que essas questões também são relevantes e altamente polêmicas, o que justificaria sua manutenção na identificação da estrutura das crenças dos atores.

Considerando os limites de realização desse trabalho, tomamos, em caráter preliminar, para viabilizar o avanço, como referência para a identificação inicial das crenças dos atores apenas uma questão, qual seja: os projetos de Garabi e Panambi são desejáveis para o desenvolvimento local e regional? A escolha dessa questão justifica-se em função de, ao nível das informações levantadas até o presente momento, considerarmos ter condições de respondê-la de forma satisfatória para construirmos um panorama das crenças dos atores envolvidos nos projetos de Garabi e Panambi, especialmente dos brasileiros.

Frente ao contexto esboçado nos PRES passamos a considerar as crenças dos atores segundo o Modelo de Coalizões de Interesses. Como visto anteriormente, o sistema de crenças é estruturado em três níveis: núcleo essencial (DCB), núcleo político (PCB) e aspectos instrumentais (SB). Nesse trabalho apresentamos algumas dimensões das DCB e das PCB identificadas. O aprofundamento do mesmo, com avanço no trabalho de campo, realizando entrevistas e a consulta documental mais aprofundada, é o passo seguinte para a qualificação do código de análise que é apresentado nos quadros 2 e 3. Neles separamos os diversos componentes procurando destacar as diferenças entre as possíveis crenças em cada componente. Provavelmente o aprofundamento do estudo implicara a inclusão de crenças intermediárias. 


\section{Componente e crenças ao nível da DCB.}

\begin{tabular}{|c|c|c|}
\hline & Componentes & Crenças \\
\hline \multirow[t]{7}{*}{ DCB } & $\begin{array}{c}\text { Relação homem } \\
\text { natureza }\end{array}$ & $\begin{array}{l}\text { - Antropocentrismo; } \\
\text { - Ecocentrismo; }\end{array}$ \\
\hline & $\begin{array}{c}\text { Uso dos recursos } \\
\text { naturais }\end{array}$ & $\begin{array}{l}\text { - Recurso natural como insumo produtivo a ser usado; } \\
\text { - Recurso natural deve ser usado com ressalvas ambientais; } \\
\text { - Preservação da natureza é prioridade; }\end{array}$ \\
\hline & $\begin{array}{l}\text { Visão sobre o } \\
\text { Estado }\end{array}$ & $\begin{array}{l}\text { - Financiador e garantidor de contratos negociados livremente no mer- } \\
\text { cado; } \\
\text { - Financiador e garantidor de interesses públicos; } \\
\text { - Regulador do mercado e garantidor de interesses públicos; } \\
\text { - Investidor e garantidor dos interesses públicos; }\end{array}$ \\
\hline & $\begin{array}{l}\text { Sinalizador da } \\
\text { viabilidade }\end{array}$ & $\begin{array}{l}\text { - Valorização das palavras das autoridades governamentais como sinali- } \\
\text { zador da viabilidade; } \\
\text { - Valorização do conhecimento científico como sinalizador da viabilida- } \\
\text { de; } \\
\text { - Valorização da participação social como requisito para a viabilidade } \\
\text { de projetos; }\end{array}$ \\
\hline & $\begin{array}{l}\text { Dimensões } \\
\text { prioritárias }\end{array}$ & $\begin{array}{l}\text { - Questões econômicas; } \\
\text { - Questões ecológicas; } \\
\text { - Questões sociais e culturais; }\end{array}$ \\
\hline & $\begin{array}{l}\text { Percepção } \\
\text { global sobre } \\
\text { sistema } \\
\text { energético }\end{array}$ & $\begin{array}{l}\text { - É preciso gerar mais energia; } \\
\text { - Hidroelétricas representam energia limpa; } \\
\text { - É preciso repensar de forma integral o sistema de geração, distribuição } \\
\text { e uso da energia. } \\
\text { - Existem alternativas de geração de energia mais sustentáveis que as } \\
\text { hidroelétricas; }\end{array}$ \\
\hline & Erro estratégico & $\begin{array}{l}\text {-Desperdiçar o potencial natural; } \\
\text {-Destruir o rio pelo seu barramento; }\end{array}$ \\
\hline
\end{tabular}

Fonte: elaboração própria. 


\section{Quadro 3}

Componente e crenças ao nível da PCB.

\begin{tabular}{|c|c|c|}
\hline & Componentes & Crenças \\
\hline \multirow[t]{6}{*}{ PCB } & Simbologia & $\begin{array}{l}\text { - Barragens representam desenvolvimento; } \\
\text { - Barragens representam interesse privados do grande capital; } \\
\text { - Barragem representam a morte do rio; }\end{array}$ \\
\hline & Consequências & $\begin{array}{l}\text { - Empregos e crescimento econômico; } \\
\text { - Desenvolvimento sustentável; } \\
\text { - Degradação ambiental; } \\
\text { - Ampliação das desigualdades sociais; } \\
\text { - Fim da cultura ribeirinha; }\end{array}$ \\
\hline & $\begin{array}{l}\text { Desenvolvi- } \\
\text { mento local }\end{array}$ & $\begin{array}{l}\text { - Contribuirão com o desenvolvimento local; } \\
\text { - Alavanca estratégica para o desenvolvimento local; } \\
\text { - Não contribuirão com o desenvolvimento local; } \\
\text {-Promoverão apenas o lucro privado de agentes de fora da região; }\end{array}$ \\
\hline & $\begin{array}{l}\text { Ações de } \\
\text { reparação }\end{array}$ & $\begin{array}{l}\text { - As medidas de mitigação impulsionarão o desenvolvimento local; } \\
\text { - As ações de mitigação tornam os projetos aceitáveis; } \\
\text { - Os danos são irreparáveis; } \\
\text { - As medidas de mitigação visam comprar apoio ao projeto; }\end{array}$ \\
\hline & Beneficiados & $\begin{array}{l}\text { - Todos serão beneficiados; } \\
\text { - As obras beneficiarão a população local e regional; } \\
\text { - As obras beneficiarão grandes agentes econômicos privados de outras } \\
\text { regiões; } \\
\text { - As barragens não geram benefícios sociais; }\end{array}$ \\
\hline & $\begin{array}{c}\text { Resultado das } \\
\text { barragens }\end{array}$ & $\begin{array}{l}\text { - Sustentabilidade social e ambiental; } \\
\text { - Energia limpa; } \\
\text { - Degradação ambiental; }\end{array}$ \\
\hline
\end{tabular}

\section{Fonte: elaboração própria.}

Ao aplicar o código formulado produz-se o esboço de identidade de crenças entre as diversas organizações que compõem o subsistema. No mapa que segue (Figura 2), esboçamos a identificação das entidades e organizações brasileiras, segundo a maior ou menor concordância em relação ao projeto das barragens. A hipótese subjacente é a da existência de duas coalizões no subsistema político analisado, sendo uma favorável e outra contrária aos referidos projetos. 
Figura 2

Mapa preliminar de atores brasileiros ${ }^{12}$ e gradiente de concordância em relação aos projetos de Garabi e Panambi.

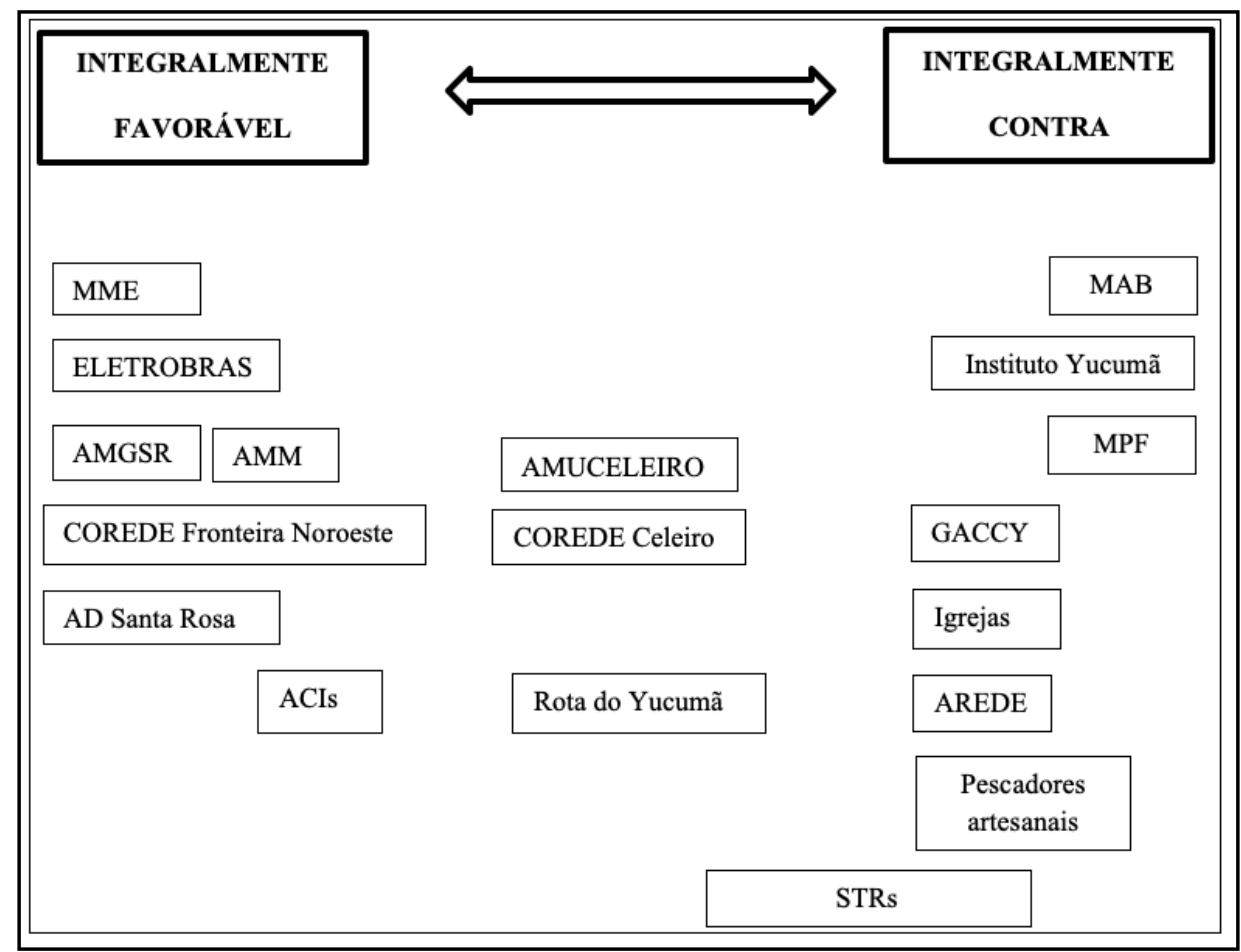

Fonte: elaboração própria.

A coalizão favorável teria crenças, ao nível das DCB, com traços marcadamente mais antropocêntricos, concebendo a natureza com um conjunto de insumos a serem utilizados produtivamente. A não utilização do potencial econômico dos mesmos tende a soar como desperdício e um erro estratégico, dado que as questões econômicas aparecem com grande relevância ante as questões ambientais. Em relação ao estado, tendem a conceber sua atuação como instituição garantidora da segurança e de contratos, cobrando do mesmo, sobretudo, maior protagonismo no financiamento dos investimentos. $O$ estado aparece como ente facilitador da ação das forças privadas, que seriam as promotoras do desenvolvimento no âmbito do livre mercado.

12 MME - Ministério de Minas e Energia; AGMSR - Associação dos Municípios da Grande Santa Rosa; AMM - Associação dos Municípios das Missões; AMUCELEIRO - Associação dos Municípios da Região Celeiro; COREDE - Conselho Regional de Desenvolvimento; AD Santa Rosa - Agência de Desenvolvimento de Santa Rosa; ACls - Associações Comerciais e Industriais; Rota do Yucumã: consórcio formado por trinta municípios com vistas a impulsionar o turismo regional na região noroeste do RS; MAB - Movimento dos Atingidos por Barragens; MPF - Ministério Público Federal; GACCY - Grupo de Arte e Cultura Costeiros do Yucumã; AREDE - Associação Regional de Desenvolvimento; STRs - Sindicatos de Trabalhadores Rurais. 
As noções que organizam essa coalizão se integram a uma "narrativa desenvolvimentista" (Arach, 2001; Ebenau, 2016). Por outro lado, também se postula uma integração "desde abajo", protagonizada por movimentos de oposição. Observa-se na coalizão dominante o intenso processo de consorciação, onde a agência estatal participa ativamente ${ }^{13}$.

Em relação ao sistema nacional de geração e distribuição de energia elétrica de ambos países a coalizão dominante apresenta uma postura menos crítica, aceitando como dada a necessidade de aumento da geração de energia hidroelétrica e, em relação ao subsistema político, aceitam com elevado grau de confiança as afirmações governamentais. Na Argentina tem sido frequente evocar a situação de crise energética, como argumento de peso, para sustentar e impulsionar a necessidade de expansão da geração hidroelétrica de energia como uma política de estado. Segundo Radovich et al. (2012, p. 57) isso é postulado a partir da ideia da existência de um "...incremento exponencial de la demanda a partir del crecimiento sostenido del PBI", principalmente para o período 2003- 2010.

Ao nível das DCB, a coalizão contrária, apresenta crenças que tendem mais ao ecocentrismo e uma visão preservacionista da natureza, que representam um elemento limitador do desenvolvimento na percepção da coalização favorável as barragens. Questões relacionadas as dimensões ecológicas, sociais e culturais aparecem com grande relevo na análise de projetos de desenvolvimento e a participação pública é tida como fundamental nos processos de decisão e legitimação dessas ações. Nesse sentido, a ação do Estado aparece como elemento regulador e garantidor dos interesses públicos e da preservação ambiental, dado que a ação de agentes puramente privados, no âmbito do livre mercado, não garante por si só os interesses públicos, sejam eles de ordem econômica, social ou ambiental. Possuem uma posição mais questionadora em relação ao sistema nacional de geração e distribuição de energia e tendem a considerar o barramento do rio como um erro estratégico. Em termos de narrativa essas crenças integram uma "narrativa antirepresista" (Arach, 2001; Ebenau, 2016).

Ao considerarmos as PCB, a coalizão favorável, tende a perceber a barragem como símbolo de desenvolvimento, apontando a geração de empregos e crescimento econômico como as consequências de sua construção. As barragens são compreendidas como geradoras de energia limpa e as ações mitigatórias tornam aceitáveis os efeitos indesejados

\footnotetext{
13 Segundo Lins Ribeiro (2008), a articulação entre os diversos atores dentro de cada campo de desenvolvimento se realiza por meio de processos históricos de estruturação de redes de relações, dentro das quais se reconhecem nudos de poder diferenciados. Caracterizadas por certa fluidez e flexibilidade, as redes podem se converter para formas institucionais afetadas por um processo de burocratização, mas assim mesmo as instituições podem integrar várias redes e mesmo cria-las em um processo de negociação em um campo político, que Lins Ribeiro (2008, p. 115) denomina de consorciação, definida como "... o processo galvanizante que transforma redes de instituições em consórcios destinados a cumprir papéis delimitados conforme definido por um dado 'projeto'. A consorciação é um processo político comandado por grupos de poder que operam em níveis mais elevados de integração. É um encadeamento que - mediante a organização de novas entidades orientadas a tarefas econômicas e administrativas - une, de fato, dentro de um projeto, instituições e capitais internacionais, nacionais e regionais [...]" O consórcio é a entidade social, econômica e política concreta que articula diferentes grupos de poder.
} 
de sua construção, que são tecnicamente previsíveis e compensáveis. Consideram que as barragens contribuirão positivamente com o desenvolvimento local e sua construção irá beneficiar sujeitos locais, regionais e nacionais.

Na coalizão contrária, ao nível das PCB, as barragens são simbolizadas como instrumentos do grande capital, que visam essencialmente os interesses privados e a obtenção de lucro, não possuindo motivações relacionadas ao desenvolvimento local. Degradação ambiental e ampliação das desigualdades sociais são as consequências apontadas por sua construção e as ações de mitigação são consideradas ações politicamente interessadas e insuficientes para compensar os danos causados. Os benefícios das obras serão dirigidos para agentes privados de outras regiões.

Contudo, ao se considerar as agências políticas e as práticas concretas adotadas ao longo da organização das ações coletivas dos movimentos contra as barragens é possível observar certas ambiguidades, tanto em relação aos projetos de grande escala (Lins Ribeiro, 1985), como também em relação a alguns posicionamentos assumidos frente a política partidária e ao estado. Nesse sentido, a fim de exemplificar essa observação, duas situações relevantes para a análise são apresentadas.

Quando se realizou em Misiones a Marcha Provincial por los Ríos Libres, em setembro de 2013,14 como densa ação coletiva para cobrar do Estado a convocação de consulta popular para decidir sobre os Projetos Garabi e Panambi, foi entrevistado um dos marchantes, integrante do Movimento dos Atingidos por Barragens (Brasil). Este interlocutor, proveniente da cidade costeira de Alecrim (Rio Grande do Sul), informou que, frente a chegada de máquinas pesadas ao local projetado para a construção da represa de Panambi - sob responsabilidade do Consorcio Energético del Río Uruguay - os militantes de sua organização, para impedir a realização de obras, trancaram a saída das máquinas e negociaram com os operadores das máquinas para que se retirassem momentaneamente do local (o que efetivamente ocorreu). Além disso, declararam-se em estado de assembleia permanente, para decidir sobre as medidas a serem tomadas em caso de não poderem reverter definitivamente a ação dessas máquinas no espaço da obra. Ao ser consultado até quando iriam continuar a luta de resistência, foi ilustrativa sua resposta, ao afirmar que iriam continuar "Até eles desistirem, ou entrar em um acordo, que eles têm que pagar pra nós antes de construir a barragem, porque depois eles não pagam [referindo-se ao pagamento de indenização que devem receber em função de sua condição de atingidos]" (Entrevista realizada em 28/09/2013). Então, se por um lado, o movimento sustenta uma tenaz oposição ao projeto das barragens - que, como vimos, implicam em ações diretas de boicote frente ao possível avanço das obras - ao mesmo tempo, para alguns de seus militantes, é necessário estabelecer, preliminarmente ao início das obras, os termos a serem considerados no processo de negociação com a coalização desenvolvimentista. Ambas

14 Organizada pela "Mesa Provincial no a las Represas", que foi criada em 2010, sendo integrada por cerca de 40 organizações sociais, ambientais e sindicais no âmbito da Província de Misiones. O transcurso da Marcha Provincial, em que se estima participaram cerca de 10.000 pessoas, se estendeu por um trajeto $157 \mathrm{~km}$, chegando na capital provincial (Posadas) no dia 28/09/2013, sendo finalizada em ato público de grande participação popular. 
posições e crenças, em princípio excludentes, não se apresentavam como incompatíveis ao informante. Assim, ao mesmo tempo em que desaprova e se opõem a construção, também manifesta em sua narrativa demandas que revelam o reconhecimento do caráter iminente do processo de construção da obra.

A segunda situação, que ilustra as tensões e ambivalências que suscita relação com a esfera política partidária, teve lugar durante assembleia realizada na localidade de Alba Posse (Misiones), em 14 de março de 2015, durante ato político convocado pela Mesa Provincial referente ao Dia Mundial de Ação contra as Barragens. Segue algumas passagens do diálogo mantido entre os interlocutores:

"...yo quisiera que la Mesa de no a la Represa en el nombre de todos nosotros presentara una carta, elaborara una carta donde los candidatos del 2015 se comprometan por esto que es defender nuestros ríos, defender a nuestra gente que van a ser despojados de sus tierras, despojados de muchas cosas, de su cultura. Defender también esa fauna y esa flora de nuestra querida provincia [...] y cómo estoy pensando que podría ser -solamente dejo la inquietud [...] que se redacte una carta donde se les dé a los candidatos, gobernador y vice-gobernador [...] que digan que van a defender el no a las represas, en primer lugar; y segundo que van a llamar a plebiscito. De manera tal que nosotros tengamos la oportunidad de elegirlo a 'esa' persona, de no regalar más nuestro 'único' capital como ciudadano para las decisiones que se tomen en nombre nuestro, en nombre del pueblo" (Participante do encontro).

Em seguida, um dirigente da Mesa e coordenador do encontro informou que na última reunião da Mesa havia se acordado que no transcurso do ano se realizaria a apresentação de um projeto de lei de Ríos libres ante o poder legislativo de Misiones, momento que se interpelaria cada um dos deputados sobre o tema das barragens. Ao final dessa fala, outra participante do evento e integrante da Mesa Provincial agrega:

"...la propuesta que yo quisiera agregar, que me parece que esto ya se había conversado... cuáles son las acciones concretas que van a realizar más allá de tomar la postura [referindo-se aos políticos] porque si no después es fácil decir 'tomo el compromiso, estoy en contra de las represas', cuando se sabe que eso puede ser un buen caudal de votos que le puede significar [...] pero me parece que si desde ya los comprometemos a que tengan que apoyar esta presentación del proyecto y los comprometemos a que expliciten de qué manera se van a comprometer, me parece que es un paso un poco más allá de que simplemente digan 'sí estamos de acuerdo y nos comprometemos a defender los ríos' [...] justamente lo que pretendemos es comprometerlos, pero comprometerlos en serio y no desde el discurso" (Participante do encontro).

Após o pronunciamento de vários participantes um dirigente ambientalista, com larga trajetória, apresenta as seguintes ponderações: 
“...el tiempo va pasando y la situación sigue siendo desde lo político, igual. Pero desde lo social es diferente. Y [...] yo me quiero referir a dos o tres cositas, nosotros hemos caminado $170 \mathrm{kms}$, hemos agitado la agenda política, comercial binacional con esa marcha [...] hemos hecho la consulta popular ${ }^{15}$ que internacionalmente tiene mucho valor, porque no es fácil que más de 120 mil personas vayan a las urnas voluntariamente sabiendo que el resultado no tiene vinculación alguna, pero sí tiene un sentido social muy importante. [...] Sinceramente, les digo con mucho respeto, a mí me sobra los dedos de la mano para ver si puedo confiar en algún dirigente político en la provincia. Me sobran dedos de la mano, me podría jugar por uno o dos y me callo. Pero sé que acá también se hicieron propuestas, sé que la mesa tiene una propuesta, yo sinceramente no creo en la dirigencia política, salvo en esos dedos [...] pero creo que nosotros ya no tenemos que seguir pensando en convencer al político a que diga no a las represas, porque las garantías de los políticos, de los representantes del pueblo, solo duran 4 años y tenemos vastísimos ejemplos de gentes que nos han dicho una cosa en un momento y en otro momento ha dicho otra cosa" (Participante do encontro). (Grifos nossos).

Ao analisar esses discursos e a reflexão surgida da experiência dos movimentos de atingidos, se aponta que existe um conhecimento, ao menos aproximado, do chamado "processo de consorciação" deque fala Lins Ribeiro (2008). Isso coloca em relevo que para qualquer obra, investimento ou projeto de gran escala a participação Estatal e das lideranças políticas é vista como fundamental para a realização, ou suspensão desses empreendimentos. A expectativa colocada em conseguir o compromisso de alguns políticos, apelando ao sentido normativo do papel que lhes cabe como "representantes do povo" - como manifesta o primeiro discurso - contrasta com a desconfiança declarada nos discursos seguintes. Não obstante estas distintas orientações, o objetivo imediato buscado pela Mesa é de impulsionar e pressionar pelo reconhecimento legal do resultado da consulta e o trâmite de um Projeto de Lei de rios sem barragens. Se, por um lado, observa-se uma concepção negativa da política, por outro lado, vemos que esta se conjuga com o esforço de acessar e propor políticas que se definem na esfera estatal. Para isso, então, é necessário interpelar e comprometer desde as bases aos dirigentes políticos.

\section{Considerações finais}

No presente artigo tratamos de caracterizar o quadro analítico da coalizão de interesses (Advocacy Coalition Framework) e testamos sua aplicabilidade para o estudo de grandes projetos de geração de energia elétrica a partir de barragens. O caso abordado é o dos projetos das barragens de Garabie Panambi, no trecho do rio Uruguaicompartilhado por Brasile Argentina.

Pode-se afirmar que esse quadro analítico mostra-se promissor para a interpretação do caso empírico considerado. Por outro lado, em termos metodológicos, o presente estudo

15 Após a referida Marcha Provincial (em outubro de 2014) durante uma semana se realizou na Provincia de Misiones uma Consulta Popular não vinculante, na qual participaram 120.418 pessoas, onde cerca de $80 \%$ delas se manifestaram pelo "Não" aos projetos Garabi-Panambi. Cabe destacar que a Lei IV - N 56 antes referida, que estabelece a obrigatoriedade da participação ativa do estado provincial na avaliação e decisão, por meio de plebiscito, sobre a viabilidade de projetos hidroelétricos, não foi operacionalizada pelo poder público. Por isso, o movimento ambientalista de Misiones organizou a referida consulta popular, considerada um ato histórico da cidadania missioneira. 
também permite apontar a necessidade da qualificação dos mecanismos analíticos de categorização e interpretação das crenças, conforme o apontado pela Advocacy Coalition Framework, questão que se coloca como desafio ao prosseguimento das pesquisas.

Considerando o estágio atual das investigações, pode-se concluir que as evidências encontradas apontam para a existência de duas coalizões de interesses, sendo uma contrária e outra favorável aos projetos de Garabi e Panambi. Cabe destacar que, os dados coletados, até o momento, precisam ser qualificados para sustentar empiricamente, com o grau de rigor e coerência necessário, conforme o quadro proposto pelo modelo de coalizão de interesses de Sabatier e Jenkins-Smith (1999), a dinâmica histórica e o comportamento destas coalizões. Assim, apesar das informações levantadas permitirem o estabelecimento de um quadro aproximado de crenças compartilhadas e das coalizões constituídas, elas ainda são insuficientes para a análise minuciosa das ações coordenadas entre os atores, que é um traço importante no comportamento das coalizões.

Em relação aos aprendizados com as políticas, o modelo se mostra promissor, pois permite evidenciar a mudança de postura por parte da ELETROBAS e EBISA quando da inclusão de variáveis ambientais mais evidentes nos projetos de 2010, reconhecendo tacitamente o tratamento inadequado dessa dimensão nos projetos anteriores. Nesse sentido, ainda cabe explorar como as mudanças nas percepções sociais e no quadro institucional sobre o meio ambiente, desde os anos 1970 até os dias atuais, impactam o subsistema da política. Essas dimensões são passíveis de análise no modelo e poderão ser posteriormente aprofundadas.

O prosseguimento dos estudos passa pela ampliação da coleta de dados empíricos. Também é uma necessidade o detalhamento das crenças e o aprofundamento da análise em relação aos atores. Destaca-se, como dimensões a serem aprofundadas, a análise em relação às arenas, as mudanças nas crenças dos atores e a articulação das ações destes ao longo do tempo, ao nível de cada país e das conexões internacionais, dado considerado fundamental para a delimitação das coalizões segundo Sabatier e Jenkins-Smith (1999). Além disso, o avanço dos estudos possivelmente implicará a consideração das barragens de Garabi e Panambi em separado, dadas suas particularidades, para a caracterização especifica dos atores, coalizões e dinâmica social em cada projeto. 


\section{Bibliografia}

Abínzano, R. C. (2000). Integración regional fronteriza 'desde abajo': nuevos sujetos colectivos, ¿̇nuevos poderes? Revista Estudios Regionales, 17, 9-29.

Arach, O. (2003). Ambientalismo, desarrollo y trasnacionalidad: las protestas sociales en torno a la represa de Yacyreta. Em E. Jelin (org.), Más allá de la nación: las escalas múltiples de los movimientos sociales (pp. 105-159). Bs. As., Argentina: Libros del Zorzal.

(2002). Ambientalismo, desarrollo y transnacionalidad en Paraguay. Consideraciones a partir de las protestas sociales en torno a la represa de Yacyretá. Cuadernos para el Debate, 16, 5-46. Disponível em https://publicaciones.ides. org.ar/sites/default/files/docs/2020/cuadernosdebate-16-2002-arach.pdf (2001). 'Entre Ríos Sí- Entre Represas No': La participación ambientalista en la oposición a la represa del Paraná Medio (Entre Ríos, 1996/97). Em A. Balazote, et al. (orgs.), Antropología y Grandes Proyectos en el Mercosur (pp. 187-212). La Plata, Argentina: Minerva.

Araújo, S.M.V.G. (2007). Coalizões de advocacia na formulação da Política Nacional de Biodiversidade e Florestas. Brasília, Brasil: IPOL/UnB.

Balazote, A., Catullo, M. R e Radovich, J. C. (2001). Antropología y Grandes Proyectos en el Mercosur. La Plata, Argentina: Minerva.

Barcelos, M. (2010). Atores, interações e escolhas: a política de silvicultura na área ambiental no Rio Grande do Sul - 2004/2009 (Dissertação Mestrado). Programa de Pós-Graduação em Sociologia, Universidade Federal do Rio Grande do Sul, Porto Alegre, Brasil.

Barros, F. L. (1996). Ambientalismo, Globalização e Novos Atores Sociais. Revista Sociedade e Estado XI, 1, 12-137.

Bartolomé, L. (2001). Combatiendo a Leviatán. La articulación y difusión de los Movimientos de Oposición a los Proyectos de Desarrollo Hidroeléctrico en Brasil (1985-91). Em A. Balazote, et al. (orgs.), Antropología y Grandes Proyectos en el Mercosur (pp. 77-102). La Plata, Argentina: Minerva.

Blake, K., Nahrath, S. e Ingold, K. (2020). Combining the Institutional Resource Regime (IRR) framework with the Advocacy Coalition Framework (ACF) for a better understanding of environmental governance processes: the case of Swiss wind power policy. Environmental Science and Policy, 112, 141-154. doi: 10.1016/j.envsci.2020.06.010

Brites, W. F. (2014). La mega-hidroeléctrica Yacyretá en el vórtice de las reconfiguraciones urbanas. El caso de las ciudades de Posadas, Argentina y Encarnación, Paraguay. Revista de Estudios Urbanos y Ciencias Sociales, 4(2), 91-107. Disponível em http://www2.ual.es/urbs/index.php/urbs/article/view/brites/0

Catullo, M. R. (2017). Proyectos de gran escala, comités populares e integración: los pioneiros de Salto Grande. Relaciones, 42 (22), 333-344. Disponível em https://ri.conicet.gov.ar/handle/11336/75245

(2020). Análisis comparativo de las relocalizaciones compulsivas rural y urbana: la represa de Itá (Alto Uruguay, Brasil) (1979-2001). Revista História: Debates e Tendências, 20 (2), 68-87. Doi: 10.5335/hdtv.20n.2.10924

Centrais Elétricas Brasileiras (ELETROBRÁS). Disponível em http://eletrobras.com/ pt/Paginas/home.aspx

Conselho Regional de Desenvolvimento da Região Celeiro (COREDE - Celeiro). (2010). Plano estratégico de desenvolvimento Região Celeiro 20 10-2030. Três Passos, Brasil: UNIJUI.

Conselho Regional de Desenvolvimento da Região Celeiro (COREDE - Celeiro). (2016). Plano estratégico de desenvolvimento regional 2015-2030. Três Passos, Brasil: COREDE CELEIRO.

Conselho Regional de Desenvolvimento da Região Fronteira Noroestes (COREDE). (2010). Plano estratégico de desenvolvimento da Fronteira Noroeste 20102030. Três de Maio, Brasil: Gráfica Sul.

Conselho Regional de Desenvolvimento da Região Fronteira Noroestes (COREDE). (2017). Plano estratégico de desenvolvimento da Região Fronteira Noroeste 2015-2030. ljuí, Brasil: UNIJUI.

Ebenau, L. A. (2016). En la construcción de una demanda de participación al Estado: la lucha anti-represista y los dilemas de la ciudadanía ambiental en 
Misiones (Argentina). Revista Perspectiva Geográfica, 11 (14), 48-62.

ELETROBRÁS/EBISA. (2010). Estudio de inventario del río Uruguay en el tramo compartido entre Argentina y Brasil. Buenos Aires, Argentina: EBISA.

Fleury, L. C. (2013). Conflito ambiental e cosmopolíticas na Amazônia brasileira: a construção da Usina Hidrelétrica de Belo Monte em perspectiva (Tese Doutorado). Programa de Pós-Graduação em Sociologia, Universidade Federal do Rio Grande do Sul, Porto Alegre, Brasil.

Florit, L. F. e Bittencourt, A. L. (2020). Conflitos em torno d'água em Santa Catarina: uma reflexão sob perspectiva ética socioambiental. Argumentos, 17 (1). 8-27. Doi: $20.32887 /$ issn.2527-2551v17n1p.8-27

Jenkins-Smith, H. C., Nohrstedt, D., Weible, C. M. e Sabatier, P. A. (2014). The advocacy coalition framework: Foundations, evolution and ongoing research. Em P.A. Sabatier; C. M. Weible (orgs.), Theories of the policy process (pp. 183224). Boulder, USA: Westview Press.

Lins Ribeiro, G. (2008). Poder, redes e ideologia no campo do Desenvolvimento. Novos Estudos, 80, 109-125.

(1999). Capitalismo transnacional y política hidroenergética em la Argentina. La Represa de Yacyretá. Posadas, Argentina: Editorial Universitaria de Misiones.

(1985). Proyectos de gran escala: hacia un marco conceptual para el análisis de una forma de producción temporaria. Em L. Bartolomé (org.), Relocalizados: Antropología Social de las Poblaciones Desplazadas (pp. 23- 47). Bs. As., Argentina: Ediciones del IDES.

Magalhães, S. (2007). Lamento e Dor: uma análise sócio-antropológica do deslocamento compulsório provocado pela construção de barragens (Tese Doutorado). Programa de Pós-Graduação em Ciências Sociais (UFPA) e École Doctoral e Vivant et Sociétés (Paris XIII), Belém, Brasil.

Ministério de Minas e Energia (MME) do Brasil. (1987). Plano Nacional de Energia Elétrica 1987/2010. Disponível em http://www.planalto.gov.br/ccivil_03/decreto/1980-1989/anexo/and96652-88.pdf

Ministério de Minas e Energia (MME) do Brasil. (2007). Plano Nacional de Energia 2030. Disponível em https://www.epe.gov.br/sites-pt/publicacoes-dados-abertos/publicacoes/PublicacoesArquivos/publicacao-165/topico-175/ PNE\%202030\%20-\%20Gera\%C3\%A7\%C3\%A30\%20Hidrel\%C3\%A9trica.pdf

Ministério Público Federal (MPF) do Brasil. (2015). Ação Civil Pública № 5000135-45.2015.4.04.711/RS. Disponível em https://www2.trf4.jus. br/trf4/controlador.php?acao=consulta_processual_resultado_pesquisa \& $t x \dagger$ Valor $=5000135452015404711 \overline{5} \&$ selOrige $\bar{m}=\mathrm{RS} \& \mathrm{chkMOs}-$ trarBaixados $=\&$ selForma $=$ NU \&hdnRefld $=8 d 4515487$ a $507 b 3836 \mathrm{fl} f d-$ 6943c6b066\&txtPalavraGerada=AMQy

Ministério Público Federal (MPF) do Brasil. (2017). Ação Civil Pública No 500013545.2015.4.04.7115/RS - Sentença. Disponível em https://www2.trf4.jus.br/trf4/ controlador.php?acao=consulta_processual_resultado_pesquisa\&txtPalavraGerada $=A M Q y \& h d n R e f l d=8 d 4515487 a 507 b 3836 \mathrm{fl}$ fd $6943 \mathrm{c} 6 \mathrm{~b} 066$ \& selFor $\mathrm{ma}=$ NU\&txtValor $=50001354520154047115 \&$ chkMostrarBaixados=\&todasfases$=\&$ todosvalores $=\&$ todaspartes $=\&$ txtDataFase $=\&$ selOrigem $=R S \&$ sistema $=\& c 0-$ digoparte=\&txtChave=\&paginaSubmeteuPesquisa=letras

Movimento dos Atingidos Por Barragens (MAB). Disponível em http://www.mabnacional.org.br/

Oviedo, A. (1997). Organización de la población frente al Proyecto Hidroeléctrico Garabí. Revista Propuesta Ecológica, 55-59.

Paim, E. S. (2017). Encogimiento del mundo y un proyecto de gran escala: el complejo hidroeléctrico Garabí. Em J. E. Castro et al. (orgs), Tensão entre justiça ambiental e justiça social na América Latina: o caso da gestão da água (pp. 239-269). Campina Grande, Brasil: EDUEPB, 2017.

Poma, A. (2017). Conflictos ambientales y democracia: las luchas contra represas como experiencias emancipadoras que construyen sujetos políticos empoderados. Em J. E. Castro et al. (orgs.), Tensão entre justiça ambiental e justiça social na América Latina: o caso da gestão da água (pp. 151-202). Campina Grande, Brasil: EDUEPB.

Prates, C. D. e Rodrigues, L. P. (2020). A Hidrelétrica Belo Monte: da controvérsia sobre energia limpa à produção da verdade científica. Ciências Sociais Uni- 
sinos, 56 (1), 80-93. doi: 10.4013/csu.2020.56.1.08

Radovich, J. C., Balazote, A. e Piccinini, D. (2012). Desarrollo de represas hidroeléctricas en la Argentina de la posconvertibilidad. Avá Revista de Antropología, $21,1-19$.

RIO GRANDE DO SUL (RS), BRASIL. (2014). Decreto No 51.595. Disponível em http:// WwW.al.rs.gov.br/filerepository/replegis/arquivos/dec\%2051.595.pdf

Sabatier, P. A. e Jenkins-Smith, H. C. (1999). The advocacy coalition framework: an assessment. Em P.A. Sabatier (org.), Theories of the policy process (pp. 117166). Boulder, USA: Westview Press.

Sabatier, P. e Weible, C. (2007). The Advocacy Coalition Framework: Innovations and Clarifications. Em P. A. Sabatier (org.), Theories of the Policy Process (pp. 189-220). Boulder, USA: Westview Press.

Santos, F. P. (2011). Coalizões de interesses e a configuração política da agricultura familiar no Brasil (Tese de Doutorado). Escola de Administração de Empresas de São Paulo da Fundação Getúlio Vargas, São Paulo, Brasil.

Sigaud, L. (1988). Efeitos Sociais de Grandes Projetos Hidrelétricos: As Barragens de Sobradinho e Machadinho. Em P. Rosa; L. Sigaud; O. Mielnik, (orgs.), Impactos de Grandes Projetos Hidrelétricos e Nucleares. Aspectos económicos e tecnológicos, sociais e ambientais (pp. 83-166). São Paulo, Brasil: Marco Zero.

Souza, E. B. C. e Brites, W. F. (2017). Dinámicas urbanas em ciudades gemelas impactadas por hidroeléctricas. Terr@Plural, 11 (2), 271-290. Doi: 10.5212/Terraplural.v.1 1 i2.0007

Vieira, D. M. (2013). Mudança institucional gradual e transformativa: uma construção de stkeholders e coalizões políticas (Tese de Doutorado). Centro de Estudos Avançados de Governo e Administração Pública da Universidade de Brasília, Brasília, Brasil.

. (2020). The discourse and coordination among advocacy coalitions: the case of Belo Monte. RAUSP, 55 (1), 86-99.

Vieira, D. M. e Gomes, R. C. (2014). Mudança institucional gradual e transformativa: a influência de coalizões de advocacia e grupos de interesses em políticas públicas. O\&S, 21 (71), 679-694. doi: 10.1590/S1984-92302014217100008.

Weible, C. M. e Sabatier, P. A. (2007). A Guide to the Advocacy Coalition Framework. Em F. Fischer; G. J. Miller; M. S. Sidney (eds.), Handbook of Public Analysis: theory, politics and methods (pp. 123-136). Boca Raton, USA: CRC Press.

Weible, C. M., Sabatier, P. A. e Mcqueen, K. (2009). Themes and Variations: taking stock of the advocacy coalition framework. The Policy Studies Journal, 37(1), 121-140.

Weible, C. M. (2018). Instrument Constituencies and the Advocacy Coalition Framework: an essay on the comparisons, opportunities, and intersections. Policy and Society, 37(1), 59-73. doi: 10.1080/14494035.2018.1417705

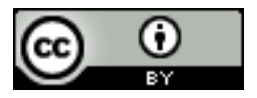

Este es un artículo de acceso abierto bajo licencia Creative Commons Reconocimiento 4.0 Internacional 